\title{
Polifonía, evidencialidad y descalificación del discurso ajeno. Acerca del significado evidencial de la negación metadiscursiva y de los marcadores de descalificación
}

\author{
Polyphony, evidentiality and rejection in discourse. \\ On the evidential meaning of metadiscursive negation and rejection discourse markers \\ Polifonia, evidencialidade e refutação. \\ Significado evidencial da negação metadiscursiva e dos marcadores de refutação \\ María Marta García Negroni \\ Universidad de San Andrés - Universidad de Buenos Aires - Conicet \\ $\diamond$
}

\begin{abstract}
Resumen: A la luz del enfoque no referencialista de la significación y no unicista del sujeto propuesto por la teoría polifónica de la enunciación, en este trabajo, argumento acerca del carácter evidencial citativo tanto de la negación metadiscursiva como de ciertos marcadores de discurso que pueden aparecer en su remplazo. Se sostiene que las instrucciones de significación asociadas a ambas formas de descalificación exigen interpretar la enunciación que las contiene como desencadenada por un discurso al que se evoca con el fin de descalificarlo, cuestionarlo o rechazarlo y cuyo origen, siempre mostrado y no dicho ni explícitamente atribuido, debe hallarse en una enunciación ajena anterior.
\end{abstract}

Palabras clave: negación metadiscursiva; marcadores de descalificación; polifonía; evidencialidad; refutación.

Resumo: À luz dos princípios não referencialistas da significação e não unicistas do sujeito proposto pela teoria polifônica da enunciação, neste trabalho, eu argumento sobre o caráter evidencial de cita da negação metadiscursiva e de alguns marcadores de discurso que podem aparecer em seu lugar. Eu afirmo aqui que as instruções semânticas relacionadas com as duas formas de refutação forçam uma interpretação da enunciação como surgida de um discurso evocado para seu questionamento o rechaço e cuja origem, sempre mostrada e não dita nem atribuída, trovasse em uma enunciação previa de outros.

Palavras-chave: negação metadiscursiva; marcadores de refutação; polifonia; evidencialidade; refutação.

\begin{abstract}
In light of non-referentialist semantic principles of enunciative polyphony, in this paper I will argue about the evidential quotative meaning contained both in metadiscursive negation as in the rejection discourse markers. It is shown that the semantic instructions associated to the meaning of these forms force to interpret the global enunciation as originated in a prior discourse which is evoked with the purpose to be disqualified o rejected.

Keywords: metadiscursive negation; rejection discourse markers; polyphony; evidentiality; rejection.
\end{abstract}

\section{Introducción}

Como se sabe, la evidencialidad suele definirse como el dominio semántico relacionado con la indicación de la fuente $\mathrm{u}$ origen de la información que el hablante comunica en su enunciado (AIKHENVALD, 2004). Se dice que la fuente es directa cuando el conocimiento de lo que hablante dice ha sido adquirido por medio de una percepción originada en alguno de sus sentidos, e indirecta cuando dicho conocimiento procede ya de una inferencia, ya de la cita de un discurso ajeno (ANDERSON, 1986; WILLET, 1988). 
Según algunos autores, el estudio de la evidencialidad debe restringirse a aquellas lenguas que la codifican en su gramática (ANDERSON, 1986; AIKHENVALD, 2004; WILLET, 1988, entre otros), de modo que solo se comunicarían significados evidenciales en sistemas lingüísticos (como el quechua, el aimara, el turco, el búlgaro, por ejemplo) que obligan al hablante a marcar mediante alguna categoría morfológica la fuente del conocimiento de aquello que enuncia. Desde una perspectiva de análisis más amplia, otros investigadores sostienen, en cambio, que aun las lenguas que no gramaticalizan los significados evidenciales (como por ejemplo, el español, el francés, el inglés, entre muchas otras) pueden igualmente disponer de recursos evidenciales y permitir el despliegue, en ciertos contextos específicos, de "estrategias evidenciales". Así, por ejemplo en español, algunos empleos específicos del modo, del tiempo y del aspecto verbal, determinadas estructuras sintácticas, ciertas construcciones adverbiales, algunos marcadores del discurso, etc. manifiestan este tipo de significados y pueden, por lo tanto, describirse como pertenecientes a alguno de los subdominios en los que se ha clasificado la evidencialidad en las lenguas en las que esta aparece gramaticalizada (cf. CHAFE, 1986; REYES, 1994; BERMÚDEZ, 2005; LÓPEZ FERRERO, 2001; LEONETTI y ESCANDELL VIDAL, 2003; CORNILLIE, 2007; ESCANDELL VIDAL, 2010; RODRÍGUEZ RAMALLE, 2008, 2014, entre otros). Siguiendo esta segunda perspectiva, en este trabajo, me detendré en el estudio de la negación metadiscursiva (que ejemplifico en (1) y (2)) y de una serie de marcadores del tipo de los que se señalan en (3)-(6) con el fin de demostrar que, análogamente a otras marcas de evidencialidad, estas formas -especializadas en las operaciones de descalificación en el discurso- vehiculizan puntos de vista evidenciales citativos.

(1) No hay nuevos rótulos que califiquen nuestra doctrina ni a nuestra ideología. Somos lo que las veinte verdades peronistas dicen. No es gritando la vida por Perón que se hace Patria, sino manteniendo el credo por el cual luchamos.

(Discurso de Juan D. Perón, 21/6/1973. Disponible en: $<$ http://www.historiadelperonismo.com/pensamientos.php $>$.)

(2) Aquí no hay nada que negociar. La democracia de los argentinos no se negocia. Se terminó para siempre el tiempo de los golpes, pero también se terminó el tiempo de las presiones, los pronunciamientos y los planteos.

(Mensaje de R. Alfonsín ante el Congreso de la Nación, 16/4/1987. Disponible en: <http://archivohistorico.educ.ar/ sites/default/files/IX_08.pdf>.)

(3) "Me cuesta creer qué mal se acostumbraron estas empresas, que se sientan a negociar pidiendo aumentos del $60 \%$ en el agua. ¡Minga que les vamos a aumentar! Primero que le den agua al pueblo", dijo Kirchner.

(La Nación, Kirchner advirtió a Aguas Argentinas, 28/1/2005. Disponible en: $<$ http://www.lanacion.com.ar/674796-kirchneradvirtio-a-aguas-argentinas $>$.)

(4) ¿¡Má qué patrimonio de la humanidad!?

EL TANGO, IGUAL QUE GARDEL, ES ARGENTINO.

(Blog La pluma de la derecha, 4/3/2009. Disponible en: $<$ http://plumaderecha.blogspot.com.ar/2009/03/ma-quepatrimonio-de-la-humanidad-el.html $>$.)

(5) Uno ve que países extranjeros apoyan a la Argentina en esta lucha votando, a nosotros que nos decían que estábamos aislados del mundo.

Cómo que estamos aislados del mundo! Si donde está representado el mundo, la @ONU_es acaba de ganar una posición que no es de Argentina...

... es la posición de naciones que tienen dignidad y defienden los derechos de sus pueblos. La de países que no quieren ser estafados.

(Tuits sucesivos de @CFKArgentina, 9/9/2014, 11:17 pm, 11:19 pm y 11:20 pm. Disponible en: <http://www.lanacion. com.ar/1725844-cristina-kirchner-el-proyecto-de-la-islademarchi-tiene-la-magnitud-del-central-park $>$.)

(6) Otra que "trabaja y se sacrifica" por el bienestar de su pueblo. Así está el mundo.

(Comentario a la nota periodística "Atribuyen a la presidenta Cristina Kirchner la compra de joyas valoradas en 2,5 millones de euros", publicada por El Mundo, 26/12/2014. Disponible en: <http://www.elmundo.es/internacional/2014/ 12/26/549da15b22601d87088b456c.html>.)

Ahora bien, si, según intentaré demostrar, en (1)-(6) debe reconocerse un significado de evidencialidad indirecta citativa, el análisis dialógico-polifónico (DUCROT, 1984, 2004; GARCÍA NEGRONI, 2009a) que propongo se aparta de varios de los presupuestos en los que en general se cimientan los estudios sobre evidencialidad. En particular, rechaza la idea de la significación lingüística como constituida por aspectos informativos o de naturaleza cognitiva, y se opone, por tanto, a la hipótesis de que el estudio del lenguaje implique evaluar las proposiciones en términos de valores de verdad o de perfilamiento intencional de la información por parte de un sujeto hablante. Al no centrar la descripción del sentido comunicado en cómo o de dónde obtuvo un sujeto hablante real el conocimiento de lo que afirma, sino en la representación polifónica y dialógica que el enunciado brinda de su propia enunciación, las páginas que siguen se inscriben en la continuidad de una investigación que busca contribuir a una caracterización semántico-argumentativa de la evidencialidad (GARCÍA NEGRONI y LIBENSON, 2014 y en prensa). 
El trabajo se organiza de la siguiente manera. En primer lugar, introduzco la perspectiva teóricometodológica de la polifonía enunciativa, en el que se fundamenta mi investigación, y en ese marco propongo una caracterización de los puntos de vista evidenciales (cf. §2). En la siguiente sección, y mediante el análisis de un cuerpo de datos constituido por ejemplos reales, tanto escritos como orales, procedentes del CREA y de diversos sitios de Internet, busco mostrar que las instrucciones asociadas a los puntos de vista evidenciales vehiculizados por la negación metadiscursiva y los marcadores del tipo de los más arriba ejemplificados exigen interpretar la enunciación que los contiene como desencadenada por un discurso al que se evoca con el fin de descalificarlo, cuestionarlo o rechazarlo, y cuyo origen -siempre mostrado y no dicho ni explícitamente atribuido en el enunciado- debe hallarse en una enunciación ajena anterior (cf. §3). Finalmente, en el último apartado (cf. $\S 4)$, presento las conclusiones del estudio.

\section{Polifonía y evidencialidad}

Como adelanté, este trabajo se inscribe en el marco del enfoque no logicista y no referencialista de la significación que plantea la teoría de la polifonía enunciativa (DUCROT, 1984, 2004). En acuerdo con los presupuestos de esta semántica instruccional, mi análisis adopta una concepción dialógica y polifónica del funcionamiento del lenguaje y propone una caracterización del sentido del enunciado como una calificación de su propia enunciación, calificación que consiste, en particular, en la puesta en escena de una multiplicidad de voces o de puntos de vista. ${ }^{1}$

Vehiculizada a través de la morfología, la sintaxis, el léxico o incluso la prosodia, la polifonía se manifiesta en dos niveles. Por un lado, en las formas de doble enunciación (DUCROT, 1984, p.203), que muestran un desdoblamiento o una multiplicación de locutores y de escenas enunciativas, como ocurre en el caso del discurso referido en estilo directo o de las comillas de la modalización autonímica (AUTHIER, 1995). Por el otro, en los diversos puntos de vista implicados en la enunciación, como sucede, por ejemplo, en la concesión, la presuposición, la ironía, la negación. Y es que, como afirma Ducrot (1984, p. 204), "el sentido del enunciado, en la representación que él da de su enunciación, puede hacer aparecer en ella voces que no son las de un locutor". Según Ducrot, esas voces son las de los distintos enunciadores que se expresan a través de la enunciación, sin que por ello se les atribuyan palabras precisas: "si hablan -afirma Ducrot- es solo en el sentido de que la enunciación es vista como la expresión de su punto de vista, de su posición, de su actitud, pero no, en el sentido material del término, de sus palabras" (1984, p. 204).
Ahora bien, si las instrucciones polifónicas obligan al interpretante del enunciado a localizar al (o a los) responsable(s) de la enunciación (i.e., el locutor en tanto tal), a reconocer los distintos puntos de vista introducidos en ella y a determinar la actitud o posicionamiento enunciativo que el locutor adopta frente a ellos (i.e., identificación, aprobación, acuerdo, distanciamiento, rechazo), la teoría polifónica nada dice acerca de los puntos de vista evidenciales vehiculizados a través del enunciado ni de cómo ellos se vinculan con la causa o el fundamento de (parte de) la enunciación en la que se expresan. Por mi parte, creo que resulta necesario proveer una descripción polifónica de estos puntos de vista, pues también ellos forman parte de la calificación que el enunciado brinda de su propia aparición. Continuando lo propuesto en trabajos anteriores (GARCÍA NEGRONI y LIBENSON, 2014 y en prensa), sostengo que las instrucciones asociadas a los puntos de vista evidenciales obligan a buscar e identificar el marco de discurso ${ }^{2}$ sobre el que se funda (parte de) la enunciación que los contiene. Y dado que los puntos de vista evidenciales vehiculizados pueden ser directos, indirectos inferenciales o indirectos citativos, dicho marco de discurso estará constituido por encadenamientos argumentativos relativos a percepciones, indicios o discursos que autentifican, justifican o desencadenan la enunciación en la que dichos puntos de vista se expresan.

Así, en el caso de los puntos de vista evidenciales directos, se dirá que su presencia exige reconocer que la enunciación en la que aparecen se presenta a sí misma como surgida de una percepción y autentificada por ella, por lo que el locutor queda representado como fuertemente comprometido con esa enunciación. ${ }^{3}$ Así, ocurre por ejemplo en (7) y (8), en los que los puntos de vista evidenciales directos (vehiculizados por la estructura sintáctica encontrar + OD + predicativo objetivo, en (7), y por la construcción de sujeto elevado con infinitivo o gerundio, analizada por Bermúdez (2004), en (8)) autentifican la enunciación al hacer de los discursos acerca de la percepción directa de una determinada situación la prueba fundante de la enunciación global (i.e., Ser testigo perceptual de X por lo tanto poder dar fe de X), que el locutor asume plenamente.

\footnotetext{
Además de las indicaciones polifónicas, esa descripción o calificación que el enunciado hace de su propia enunciación consiste en una serie de instrucciones argumentativas, ilocucionarias y causales que el interpretante también debe llevar a cabo para poder acceder al sentido del enunciado (cf. DUCROT, 1984).

2 Inspirado en la noción de "espace discursif" propuesta por Anscombre $(1989,1992)$, el concepto de "marco de discurso" que aquí propongo se define como los discursos argumentativos que se presentan como el lugar a partir del cual surge o se desencadena la enunciación actual.

3 Me distancio así fuertemente de Reyes (1994, p.25), para quien el significado evidencial solo "se produce cuando el hablante tiene la intención de expresar algún escrúpulo acerca del conocimiento de lo que afirma, especialmente cuando quiere indicar que es algo que ha inferido o que le han contado".
} 
(7) La encontré cambiada a París.

(8) Veo venir al jefe.

En lo que se refiere a los puntos de vista evidenciales indirectos, se dirá que forma parte del sentido del enunciado que los contiene reconocer que el posicionamiento enunciativo del locutor es más distante y ello tanto si se trata de puntos de vista evidenciales indirectos inferenciales como citativos. En el caso de los inferenciales, sus instrucciones instan a comprender la enunciación no como plenamente asumida por el locutor en la medida en que se la presenta como si fuera el resultado de algún tipo de razonamiento (conjetura, deducción, etc.) a partir de discursos argumentativos relacionados con indicios perceptuales o discursivos (i.e., Veolescucho/dicen X por lo tanto infiero Y). Por su parte, las instrucciones asociadas a los citativos hacen leer la enunciación como desencadenada o motivada por otro discurso cuyo origen no aparece explícitamente identificado y respecto del cual el locutor puede mostrar actitudes de distanciamiento diverso, que van desde la simple precaución epistemológica hasta el rechazo absoluto (i.e., Dicen $X$ sin embargo $X$ no me constal Dicen $X$ sin embargo no $X$ ).

A modo de ejemplo de estos significados evidenciales indirectos inferenciales y citativos, puede considerarse el fragmento (9), titular y copete (o entradilla) de una nota periodística publicada pocos días después de la muerte del fiscal Nisman: ${ }^{4}$

(9) Nisman habría pensado en pedir la detención de Cristina

La denuncia del fiscal por encubrimiento a favor de los iraníes. En el tacho de basura de su departamento se habría encontrado una versión original que contiene esa medida. La final tiene tachaduras.

(Clarin, 1/2/2015. Disponible en: <http://www.clarin.com/ politica/nisman-cristina-denuncia_original-amia_0_129587 0451.html>.)

Desde una perspectiva polifónica de la enunciación que tome en consideración, como propongo, la existencia de puntos de vista evidenciales, comprender el titular de (9) consiste, entre otras cosas, en interpretar esa enunciación como si fuese el resultado de un razonamiento y ello, en virtud de la presencia de un punto de vista evidencial indirecto de carácter inferencial. Vehiculizado

\footnotetext{
4 El fiscal Alberto Nisman, quien tenía a su cargo la causa del atentado contra la AMIA (Asociación Mutual Israelita Argentina), fue encontrado muerto en su departamento en la ciudad de Buenos Aires pocos días después de haber denunciado en un programa de televisión a la presidenta Cristina F. de Kirchner y a otros funcionarios de su gobierno por supuesto encubrimiento de un grupo de sospechosos en la causa AMIA.
}

por el condicional habría pensado, dicho punto de vista evidencial exige buscar el fundamento o la razón de la enunciación conjetural que lo contiene en algún indicio previo a partir del cual ella queda autorizada. El enunciado no presenta así un locutor que declara que Nisman pensó en pedir la detención de la presidenta Kirchner, sino que muestra un locutor que, basado en ciertas pruebas o indicios (i.e., la existencia y el hallazgo de una segunda versión de la denuncia contra la presidenta), afirma matizadamente su conclusión (i.e., Se encontró una segunda versión de la denuncia contra la presidenta por lo tanto infiero que Nisman pensó en pedir la detención de Cristina). Y ello es, precisamente, lo que en el plano de lo dicho (y no ya en el de lo mostrado mediante el empleo del condicional) se sostiene explícitamente en el último párrafo de la misma nota periodística (cf. (10)):

(10) En las declaraciones que hizo a los medios para explicar el contenido y el alcance de su acusación contra el Poder Ejecutivo, Nisman no hizo alusión a un pedido de desafuero y de detención contra la Presidenta y el canciller. Pero en su casa se encontraron pruebas que indican que pensó hacerlo, tanto que lo escribió. (Clarin, 1/2/2015. Disponible en: <http://www.clarin.com/ politica/nisman-cristina-denuncia_original-amia_0_1295 870451.html>.)

Pero(9) contiene además otro punto de vista evidencial, también vehiculizado por un condicional epistémico (KRONNING, 2005): se habría encontrado (en "En el tacho de basura de su departamento se habría encontrado una versión original que contiene esa medida"). Pero a diferencia de habría pensado, este segundo condicional reviste un carácter citativo en tanto obliga a reconocer la existencia de un discurso previo (cuyo origen, mostrado simplemente a través de la morfología verbal, podría encontrarse en fuentes policiales o judiciales) sobre el que se apoya la enunciación que lo incluye. Como en el caso anterior, el locutor no asume plenamente este punto de vista evidencial. Al contrario, marca su distancia frente a él y al hacerlo no queda comprometido en la continuidad discursiva con discursos que podrían surgir a partir de él, como sí ocurriría en el caso de (11):

(11) En el tacho de basura de su departamento se encontró una versión original que contiene esa medida.

En efecto, presentada por el pretérito perfecto simple se encontró como motivada por una decisión propia del responsable de la enunciación que eligiría comunicar ese enunciado (DUCROT, 1984, p. 186), la imagen de la enunciación que (11) brinda es la de un locutor que se identifica con el punto de vista relativo a 
lo encontrado en el tacho de basura y con el que, por lo tanto, queda fuertemente implicado. De hecho, si luego de la enunciación de estos enunciados, se supiera que no existía tal versión de la denuncia, solo al autor de (11) -y no al de (9)- podrá reprochársele el haber mentido, inventado o inducido a error.

En suma, los puntos de vista evidenciales forman parte de la calificación que el enunciado brinda de su propia aparición y deben por lo tanto ser incluidos en la descripción polifónica del sentido. Y esto es así en la medida en que ellos exigen la búsqueda e identificación del marco de discurso previo (i.e., discursos argumentativos en los que intervienen como primer miembro del encadenamiento representaciones discursivas de percepciones, indicios o voces previas) sobre el que se funda la enunciación a través de la que se expresan, e implican posicionamientos enunciativos diversos por parte del locutor (i.e., desde la asimilación con el punto de vista evidencial hasta su rechazo absoluto pasando por el distanciamiento y la precaución epistemológica). El próximo apartado estará destinado al análisis de los puntos de vista evidenciales citativos vehiculizados en particular por las formas que nos ocupan: la negación metadiscursiva y los marcadores especializados en la descalificación de discursos previos.

\section{Negación metadiscursiva, marcadores de descalificación y puesta en escena de puntos de vista evidenciales citativos}

Como se recordará, Ducrot distingue tres tipos de negación: la polémica, la descriptiva y la metalingüística. Si la descriptiva es analizada como un derivado delocutivo de la polémica y permite "representar un estado de cosas, sin que su autor presente su palabra como opuesta a un discurso adverso" (DUCROT, 1984, p.216-217), la negación polémica siempre supone la presencia de dos puntos de vista antagónicos e internos al propio discurso. Dichos puntos de vista son atribuidos a distintos seres discursivos, los enunciadores $E_{1}$ y $E_{2}$ : el primero es el responsable del punto de vista positivo subyacente, el segundo constituye el rechazo del primero y representa la perspectiva con la que el locutor se homologa (DUCROT, 1984; NØLKE, 1992). En cuanto a la negación metalingüística, Ducrot la caracteriza como una negación que contradice los términos mismos de una palabra efectiva que se pretende refutar, por lo que siempre opone dos locutores diferentes. Para el lingüista francés, es justamente en el marco de esta refutación de un locutor adverso que la negación adquiere ciertas características particulares, a saber:

- puede anular las presuposiciones del enunciado positivo previo;

- puede tener, "en lugar de su efecto habitualmente 'reductor', un valor ascendente" (DUCROT,
1984, p. 217). En efecto, según Ducrot, "se puede decir 'Pedro no es inteligente, es genial', pero solo en respuesta a alguien que efectivamente calificó a Pedro de inteligente" (1984, p. 217).

Y son básicamente estas dos propiedades las que la distinguen con claridad, según Ducrot, de la negación polémica, que solo tiene un efecto descendente (i.e., lectura "menos que") y que siempre conserva las presuposiciones del enunciado positivo subyacente.

Por mi parte, y tal como señalé en un trabajo anterior (GARCÍA NEGRONI, 2009b), considero que la negación metalingüística no siempre contradice los términos mismos de una palabra efectiva previa; tampoco comparte con la negación polémica su efecto "descendente". Según mi análisis, lo que caracteriza esta negación es su capacidad para cuestionar y rechazar el marco discursivo impuesto por un discurso anterior para así situarse en un marco diferente del rechazado. Y ello ya sea que se trate de su empleo metalingüístico propiamente dicho (es decir, de aquellos casos en los que la negación cuestiona el empleo de un término o de un grupo de palabras del interlocutor en virtud de una regla sintáctica, morfológica, social, etc. que es puesta en evidencia por el enunciado posterior que introduce la rectificación), ya sea que se trate de su empleo metadiscursivo, en el que la negación descalifica la representación surgida de un discurso efectivo del interlocutor en una intervención previa, o de un discurso evocado dialógicamente en la propia enunciación negativa descalificadora. Este empleo metadiscursivo es el que aparece en (1) y (2) y es también aquel con el que se relacionan, precisamente, los marcadores de descalificación del tipo de minga que, ma qué, cómo que, otra que ejemplificados en (3)-(6) y que, tal como lo muestran las paráfrasis (3a)-(6a), pueden aparecer en su remplazo: ${ }^{5}$

(3) a. " ¡No, no les vamos a aumentar! Primero que le den agua al pueblo", dijo Kirchner.

(4) a. ¡No, no es patrimonio de la humanidad! El tango, igual que Gardel, es argentino.

(5) a. ¡No, no estamos aislados del mundo! Si donde está representado el mundo, acaba de ganar una posición que no es de Argentina, es la posición de naciones

\footnotetext{
Las formas minga y cómo pueden ocurrir, con un valor de descalificación semejante, sin la conjunción que (cf., por ej., -“¿Extraña a Néstor Kirchner?/-Minga lo voy a extrañar, para nada...", o "Messi: Es una locura ... ¿cómo no voy a saludar a un nene?’). Propio del español rioplatense (al igual que minga (que) y otra que), ma qué puede alternar con el general qué (cf. ¡Ma qué va a haber venido!/ ¡Qué va a haber venido!). Respecto de su escritura y si bien la forma más frecuente es $m a$ qué, también se registran má qué, ma' que, ma' qué y ma qué. Para un estudio de ma qué y otra que, podrá consultarse García Negroni (2012).
} 
que tienen dignidad y defienden los derechos de sus pueblos. La de países que no quieren ser estafados ...

(6) a. No, no "trabaja" y no "se sacrifica" por el bienestar de su pueblo.

Es más, al igual que la negación metadiscursiva, las enunciaciones con los marcadores de descalificación aparecen normalmente seguidas (con menos frecuencia, precedidas) de un enunciado de rectificación $Y$, con el que el locutor se identifica y que explicita el nuevo marco de discurso que, según lo que en el enunciado se sostiene, es el adecuado para la representación discursiva de la situación de la que se trata. Ese nuevo marco podrá ser o bien el contrario del rechazado, o bien uno diferente o bien el extremo, por lo que el efecto de la enunciación negativa podrá ser contrastivo (lectura "contrario de"), diferenciador ("distinto de") o ascendente (lectura "más que").

Así, y análogamente a lo que ocurre en (1), en el que el enunciado de rectificación la Patria se hace manteniendo el credo por el cual luchamos constituye el nuevo marco de discurso con el que el locutor se homologa y que se revela como fuertemente distinto del descalificado por la negación metadiscursiva (se hace Patria gritando la vida por Perón), en (4), el tango, igual que Gardel, es argentino es presentado como el nuevo marco discursivo que el locutor propone en remplazo del vehementemente cuestionado por el marcador ma qué (el tango es patrimonio de la humanidad).

(1) No es gritando la vida por Perón que se hace Patria, sino manteniendo el credo por el cual luchamos.

(4) ¿¡Má qué patrimonio de la humanidad!? El tango, igual que Gardel, es argentino. ${ }^{6}$

Por su parte, en (2) y (3), y, dada la no explicitación del enunciado de rectificación, es la lectura abiertamente contraria al marco de discurso descalificado -i.e., la pretensión por parte de los carapintadas de negociar una solución política para los juicios a los represores de la dictadura militar, ${ }^{7}$ en (2); el reclamo de la empresa Aguas Argentinas de un aumento de tarifas, en (3)-, la que queda habilitada: no hay nada en absoluto que negociar, la democracia de los argentinos es innegociable, en (2); las tarifas seguirán siendo las mismas, en (3).

\footnotetext{
6 En las enunciaciones con negación metadiscursiva, el enunciado de rectificación $Y$ puede aparecer introducido por la conjunción de coordinación adversativa exclusiva sino (KOVACCI, 1990, p. 152) (cf. (1)) o como enunciado independiente (cf. (2)). En cambio, y dado que sino siempre exige una negación sintáctica precedente, en el caso de las enunciaciones con marcadores de descalificación $Y$ solo puede aparecer como enunciado independiente.

7 Se conoce como "carapintadas" a un grupo de militares nacionalistas que llevaron a cabo entre 1987 y 1990 una serie de alzamientos contra el gobierno democrático argentino.
}

(2) Aquí no hay nada que negociar. La democracia de los argentinos no se negocia.

(3) ¡Minga que les vamos a aumentar!

Finalmente, en (6), y de modo semejante a lo que ocurre en enunciados del tipo A mí no me gusta el cine; me encanta, en los que la rectificación $Y$ introduce un marco de discurso más fuerte en el mismo sentido del rechazado, las enunciaciones con el marcador otra que, especializadas en el rechazo de marcos de discurso previos por débiles, también autorizan la lectura "más que". ${ }^{8}$ De este modo, a la descalificación irónica que surge del empleo de las comillas polémicas que marcan la no coincidencia del discurso consigno mismo (AUTHIER, 1995) ${ }^{9}$ en torno de trabaja y se sacrifica, se suma el efecto ascendente que lleva a la interpretación del tipo no trabaja ni se sacrifica en absoluto.

Otra que "trabaja y se sacrifica" por el bienestar de su pueblo.

Por otra parte, tanto la negación metadiscursiva como las enunciaciones con marcadores de descalificación admiten como continuidad discursiva un enunciado de la forma si $P$, en el que la conjunción si introduce la justificación del rechazo del marco de discurso previo. Así en (12),

$$
\begin{aligned}
& \text { A: - Juan vino ayer. } \\
& \text { B: - No, no vino ayer. ¡Si está enfermo! }
\end{aligned}
$$

el locutor no solo rechaza la representación surgida del discurso de A (i.e., la venida y la presencia de Juan el día anterior), sino que además justifica el porqué de su posicionamiento mediante un argumento, que presenta como conocido por ambos, acerca de la enfermedad de Juan (cf. presencia del marcador puesto que, especializado en la introducción de causas presentadas como conocidas, en la paráfrasis (12a)).

(12) a. B: - No, Juan no vino ayer, puesto que, como bien sabés, está enfermo.

Análogamente, en (5), al rechazo de la representación discursiva según la cual los argentinos estaríamos aisla-

\footnotetext{
8 La presencia del enunciado de rectificación $Y$ es obligatoria para indicar cuál es la lectura deseada solo cuando el efecto de la negación es diferenciador o ascendente. En el caso de las enunciaciones con otra que, en cambio, y dado que ellas solo habilitan la lectura ascendente, es esta la única lectura posible cuando el enunciado de rectificación $Y$ no aparece explicitado.

9 Como señala Authier (1995), este tipo de comillas señala la presencia extraña en el discurso de palabras marcadas como pertenecientes a otros y al hacerlo pone en evidencia la interdiscursividad mostrada.
} 
dos del mundo, se suma la justificación, dada como evidente y aceptada por todos en la situación de la que se trata, introducida por $s i$ : las Naciones Unidas apoyan la posición de la Argentina. De modo semejante, en (3) y (6), la no aceptación, por parte del locutor, del pedido de un aumento de tarifas de la empresa Aguas Argentinas y el comentario a la nota periodística sobre el supuesto valor de la joyas de la presidenta, en el que se descalifican los discursos acerca de que la presidenta trabajaría y se sacrificaría por el pueblo admitirían como continuidades discursivas posibles prótasis encabezadas por si que justificarían los mencionados rechazos y descalificaciones (cf. (3') y (6')):

(5) Cómo que estamos aislados del mundo! Si donde está representadoelmundo,la@ONU_es acabadeganar una posición que no es de Argentina... es la posición de naciones que tienen dignidad y defienden los derechos de sus pueblos. La de países que no quieren ser estafados.

(3') ¡Minga que les vamos a aumentar! Si no hicieron las inversiones a las que se comprometieron.

(6') Otra que "trabaja y se sacrifica" por el bienestar de su pueblo. Si vive comprándose joyas.

Pero además de los diversos efectos de lectura que generan, de la presencia obligatoria del enunciado de rectificación $Y$ para explicitar la lectura deseada en los casos señalados y de la posibilidad del enunciado de justificación Si $P,{ }^{10}$ ambos tipos de enunciaciones refutativas (es decir, las enunciaciones con negación metadiscursiva y las enunciaciones con marcadores de descalificación) tienen otra propiedad fundamental en común. $\mathrm{Y}$ es que tanto unas como otras manifiestan puntos de vista evidenciales citativos que obligan a buscar y a identificar un marco de discurso previo que se presenta como el desencadenante de la enunciación actual, la que por su parte lo evoca para rechazarlo.

Mostrado y no dicho, el origen de ese marco de discurso puede ser más o menos cercano, más o menos difuso, más o menos determinable. Así, mientras que en el diálogo, el punto de vista evidencial vehiculizado por la negación o el marcador insta a hallar el origen del decir descalificado, cuestionado o rechazado que desencadena la enunciación negativa de $\mathrm{B}$ en el discurso inmediatamente anterior del interlocutor A (cf., por ejemplo (13) y (14)),

(13) - ¿Cómo que depende de la avería? No me venga con gilipolleces... o tienen taller móvil o no lo tienen. Es así de simple.

Carlos se aprieta el puente de la nariz.

- No, no es así de simple. Un taller móvil es, por así decirlo, para primeros auxilios.

(Nuño, C., Clarita y su mundo de Yupi, Ed. CreateSpace, 2013, p. 71)
(14) Mirá, zurdito, afuera está preguntando por vos una que dice que es tu hermana. Está con un auto y dos amigas. Nos las vamos a coger a todas... - lo apretó el zumbo.

- Minga que va a estar mi hermana con un auto. $\mathrm{Si}$ no tiene registro...

(Zuker, C., El tren de la victoria, Buenos Aires: Sudamericana, 2003, p. 77).

en el discurso monologal de un único locutor, el origen del decir evocado dialógicamente puede resultar más lejano o más indeterminado. En este último caso, en efecto, las instrucciones asociadas a los puntos de vista evidenciales llevan a hallar ese origen ya en el discurso de un locutor más o menos identificable en la "memoria discursiva" (como ocurre en (1), (2), (5) o (6)), ${ }^{11}$ ya en un decir más o menos atribuible en el contexto inmediato de enunciación (cf. (3)), ya en una voz colectiva y más cristalizada como la de la doxa o la del folclore (como es el caso de (4)), En las paráfrasis (1b)-(6b), que siguen, las glosas del tipo como decís, como dice/diría $X$, como se dice, etc., con el marcador evidencial o mediativo como $V$ de decir $(e l+$ un) $X$ (ANSCOMBRE, 2011), permiten explicitar a quién (i.e., a un locutor identificable en el contexto discursivo, a un locutor indeterminado, a la voz indefinida del SE, etc.) se atribuye el origen del discurso descalificado. Por su parte, las glosas en las paráfrasis (13b)-(14b) ponen de manifiesto que el origen del marco de discurso rechazado en esas intervenciones está en la enunciación previa del interlocutor.

(1) b. No hay nuevos rótulos que califiquen nuestra doctrina ni a nuestra ideología, como dicen los montoneros. Somos lo que las veinte verdades peronistas dicen. No es gritando la vida por Perón que se hace Patria, como ellos dicen, sino manteniendo el credo por el cual luchamos.

(2) b.Aquí no hay nada que negociar, como exigen los carapintadas. La democracia de los argentinos no se negocia, como ellos quieren.

(3) b....estas empresas, que se sientan a negociar pidiendo aumentos del $60 \%$ en el agua. " ¡Minga que les vamos a aumentar, como esas empresas pretenden! Primero que le den agua al pueblo", dijo Kirchner.

(4) b. ¿iMá qué patrimonio de la humanidad, como dicen/ como se dice!? El tango, igual que Gardel, es argentino.

\footnotetext{
10 En García Negroni (en prensa a), se describen en detalle otras propiedades que ambos tipos de enunciaciones refutativas tienen en común.

${ }^{11}$ El concepto de "memoria discursiva" refiere a un "conjunto complejo, preexistente y anterior [...] constituido por series de tejidos de indicios legibles, que constituyen un cuerpo socio-histórico de huellas" (PÊCHEUX, 1990, p. 286).
} 
(5) b.Cómo que estamos aislados del mundo, como dice la oposición! Si donde está representado el mundo, la@ONU_es acaba de ganar una posición que nos apoya.

(6) b. Otra que "trabaja y se sacrifica", como dicen los oficialistas, por el bienestar de su pueblo. Así está el mundo.

(13) b.- No, no es así de simple, como usted dice. Un taller móvil es, por así decirlo, para primeros auxilios.

(14) b. - Minga que va a estar mi hermana con un auto, como vos decís. Si no tiene registro...

Queda así configurada, tanto en la réplica dialogal como en el discurso monologal, una escena refutativa en la que a las instrucciones semántico-pragmáticas asociadas a la negación metadiscursiva y a los marcadores de descalificación pueden sumarse las del futuro perifrástico (FP) en su empleo evidencial citativo. ${ }^{12}$ En efecto, la ocurrencia del FP evidencial en enunciados exclamativos o interrogativos con marcadores de descalificación del tipo ; (ma) qué FP!, ;cómo FP!, imirá si FP!, iminga (que) FP! presenta un locutor que descalifica y rechaza un marco de discurso previo, cuyo origen -mostrado precisamente a través de la perífrasis de futuro y del marcador de descalificación- puede hallarse ya en la intervención previa del interlocutor (es el caso de (14), así como el de (15) y (16)), ya en un discurso al que simplemente se alude o que se evoca dialógicamente en la propia enunciación descalificadora (es el caso de (17)).

(15) DIMAS. - O sea, que si la trincan ya sabe dónde vivimos.

BEGO. - ¡Ella qué va a saber! Cuando fui a ver a Riki la dejé en una cafetería y no se movió. Ella se queda donde le digas, y por el nombre de la calle no te preocupes, casi no sabe leer.

(CREA, Mendizábal, R., Mala yerba, Madrid, MarsóVelasco, 1989)

(16) Samaiasis escribió: lo que vi es que la diferencia en la polifonia de uno y otro es muy amplia... 32 para el p35 y 128 para el p105... la polifonia influye cuando el piano suena con sus sonidos, o enchufado a la pc tambien????? o en la pc la polifonia ya la hace el cpu???... alguien podrìa desasnarme???

\footnotetext{
12 En García Negroni (en prensa b) se estudian algunos empleos "dislocados" del futuro morfológico (FM) y del futuro perifrástico (FP) que permiten el desarrollo, entre otros, de un significado evidencial citativo. Se argumenta que con este significado, uno y otro tiempo configuran escenas enunciativas claramente distintas: mientras que la mostrada por el FM es la de un locutor que concede un discurso previo o atribuido anticipadamente a otro, la surgida por la ocurrencia del FP es la de un sujeto que descalifica y rechaza, al modo de la negación metadiscursiva, ya un enunciado efectivamente pronunciado por otro(s), ya un discurso al que simplemente se alude o que se evoca en la propia enunciación.
}

- No hombre, ¡cómo va a tener que ver la polifonía del motor interno de sonidos con la polifonía cuando utilizas un motor de sonido externo!

(Foro: Polifonía de un piano digital. Ayuda. Disponible en: $<$ http://www.hispasonic.com/foros/polifonia-piano-digitalayuda/477771>.)

(17) Lunati: "Mi viejo era hincha de River, pero... ¡Mirá si voy a tener un santuario en el baño!"

El polémico árbitro retomó aquella versión que indicaba que un funcionario de la AFIP encontró su baño "como el Monumental".

(Infobae, "Lunati: Mi viejo era hincha de River, pero... ¡Mirá si voy a tener un santuario en el baño!”, 14/11/2014. Disponible en: <http://www.infobae.com/2014/11/21/ 1610324-lunati-mi-viejo-era-hincha-river-pero-mira-sivoy-tener-un-santuario-el-bano $>$.)

Ahora bien, si como queda dicho, en (1)-(6) y (13)(17), es la presencia de la negación metadiscursiva o del marcador de descalificación la que insta a buscar y a identificar el origen del marco de discurso rechazado sobre el que se funda la enunciación global, este no es el caso de todas las enunciaciones negativas. Así, por ejemplo, en (18) y (19), la negación polémica, que muestra su enunciación como el choque de dos puntos de vista antagónicos, lleva a interpretar que el locutor, al asimilarse al enunciador del rechazo $\mathrm{E}_{2}$, no se opone a un locutor más o menos determinable o identificable en el contexto, "sino a un enunciador $\mathrm{E}_{1}$, que él mismo pone en escena en su discurso" (DUCROT, 1984, p. 217). Así, dado que el punto de vista positivo subyacente en la negación polémica es interno al propio enunciado y dado que, en consecuencia, la negación no exige identificar el origen de ese punto de vista en un discurso previo y distinto del que lo contiene, esta negación no vehiculiza ningún significado evidencial.

(18) Los abogados lograron romper la ventana para entrar al vestidor pero no pudieron evitar el crimen.

(La Nación, 22/8/2015. "Crimen del country: el empresario Fernando Farré se negó a declarar y la fiscal pidió peritajes").

(19) Che, Juan no vino hoy a la reunión.

En efecto, si en las negaciones polémicas el locutor se homologa con $E_{2}$-lo que explica que las continuidades discursivas se relacionen siempre con ese punto de vista negativo (por ej., en (18), por lo tanto la mujer murió, o en (19), va a tener que pedir que le cuenten lo que ocurrió)- y se opone al punto de vista positivo $\mathrm{E}_{1}$, las instrucciones contenidas en la significación de estas oraciones nada dicen respecto de a quién debe atribuirse ese $\mathrm{E}_{1}$. 
Pero puede ocurrir que a la negación se sume una entonación particular (por ejemplo, de reproche), mediante la cual quede mostrado en la enunciación que es al interlocutor a quien se atribuye el origen del discurso positivo contrario. Es lo que sucede, por ejemplo, en (20), en el que, según la imagen que del enunciado de $\mathrm{A}$ brinda la réplica defensiva de $\mathrm{B}$, el enunciado negativo de $\mathrm{A}$ contenía un punto de vista evidencial, es decir un punto de vista que obliga a buscar y a identificar (en este caso, en un discurso previo del locutor B) el origen de la aserción acerca de la asistencia de Juan a la reunión en cuestión. En otras palabras, al negarse a aceptar la atribución de ese punto de vista evidencial (yo nunca dije que iba a venir), la intervención de B revela que, al menos para él, la negación de A revestía carácter metadiscursivo.

$$
\begin{aligned}
& \text { A: - Che, Juan no vino hoy a la reunión. } \\
& \text { B: - Yo nunca dije que iba a venir. }
\end{aligned}
$$

En síntesis, a diferencia de la negación metadiscursiva que vehiculiza puntos de vista evidenciales citativos, las instrucciones polifónicas contenidas en la significación de la negación polémica no exigen la determinación de a quién debe atribuirse el punto de vista positivo subyacente $\mathrm{E}_{1}$ al que se opone el locutor, responsable de la enunciación negativa. De modo que si esa exigencia forma parte del sentido, ello es porque a través de la enunciación negativa -que debe interpretarse necesariamente entonces como metadiscursiva- se expresa un punto de vista evidencial citativo (en (20), manifestado en la prosodia), con la instrucción de búsqueda del origen de ese discurso ajeno que, evocado dialógicamente en la enunciación, quedará descalificado, cuestionado o rechazado.

\section{A modo de cierre}

A la luz del enfoque no referencialista de la significación y no unicista del sujeto propuesto por la teoría polifónica de la enunciación, en este trabajo argumenté acerca del carácter evidencial citativo tanto de la negación metadiscursiva como de los marcadores especializados en la descalificación de discursos ajenos. Para dar cuenta de ese sentido comunicado, no centré la descripción en cómo o de dónde un sujeto hablante real habría obtenido la información o el conocimiento de lo que afirma, sino en la representación dialógica y polifónica que el enunciado brinda de su propia enunciación. Caractericé así, en primer lugar, el significado evidencial vehiculizado por los puntos de vista evidenciales directos e indirectos como la instrucción de búsqueda del marco de discurso (i.e., discursos argumentativos en los que intervienen como primer miembro del encadenamiento representaciones discursivas de percepciones, indicios o discursos) que se presenta como el lugar a partir del cual surge o se desencadena la enunciación global y respecto del cual el locutor muestra distintas actitudes.

En el caso de la evidencialidad citativa, señalé que dichas actitudes pueden ir desde la simple precaución epistemológica hasta el rechazo absoluto. Así, por ejemplo, los puntos de vista evidenciales vehiculizados por el condicional epistémico o por el futuro morfológico (por ejemplo, habría en Habría aumento de tarifas o será en Será inteligente, pero ese detalle se le escapó) instan a reconocer la existencia de un marco de discurso previo sobre el que se apoya la enunciación que los incluye y a interpretar que ese marco de discurso es evocado con precaución (en el caso del condicional) o solo concedido el tiempo que dure la enunciación (en el caso del futuro). Por su parte, la presencia de la negación metadiscursiva o de los marcadores de descalificación (acompañados eventualmente por el futuro perifrástico) construye una escena refutativa en la que el marco de discurso desencadenante o fundante de la enunciación actual en la que se lo evoca resulta siempre descalificado, cuestionado, rechazado.

En segundo lugar, insistí en que, en las enunciaciones refutativas, el reconocimiento y la identificación del origen de la enunciación evocada y rechazada es el resultado de una instrucción que resulta ineludible para poder acceder al valor semántico completo de estos enunciados. Es precisamente en esta instrucción relativa al punto de vista evidencial vehiculizado por la negación metadiscursiva en la que reside una de las diferencias semánticas fundamentales con la negación polémica: esta última nunca insta a buscar e identificar fuera de ella el origen del punto de vista positivo subyacente.

Finalmente, y dado que, tal como he tratado de mostrar aquí, la evidencialidad debe definirse en relación con la representación polifónica de los puntos de vista evidenciales $-\mathrm{y}$ no con la indicación de la fuente o del origen de la información que el hablante comunicaría en su enunciado-, los elementos de sentido por ellos vehiculizados pueden hallarse en distintos niveles de profundidad del análisis semántico. Así, por ejemplo, si en enunciados del tipo Habría aumento de tarifas, el punto de vista evidencial manifestado por el condicional obliga a interpretar que lo que le sigue es un discurso ajeno que es retomado con precaución, en el caso de las negaciones metadiscursivas y de los marcadores de descalificación aquí tratados, el marco de discurso ajeno subyace a la enunciación refutativa en la que se lo evoca. Y es que, tal como afirma Ducrot (1987), frente al análisis semántico horizontal típico de la filosofía del lenguaje angloamericana, la teoría de la polifonía propone un análisis vertical que permite dar cuenta de la superposición de discursos y puntos de vista (entre los que figuran los evidenciales) que constituyen el sentido del enunciado. 


\section{Referencias}

AIKHENVALD, Alexandra. Evidentiality. Oxford: Oxford University Press, 2004.

ANDERSON, Lloyd. Evidencials, Paths of Change, and Mental Maps: Typologically Regular Asymmetries. In: CHAFE, W.; NICHOLS, J. (eds.). Evidentiality: The Linguistic Coding of Epistemology Norwood: Ablex Publishing Corporation, 1986. p. 273-312.

ANSCOMBRE, Jean-Claude. Thème, espace discursif et représentations événementielles. In: ANSCOMBRE, J.-C.; ZACCHARIA, G. (éds.). Fonctionnalisme et pragmatique: à propos de la notion de thème. Milan: Unicopli, 1989. p. 43-150.

ANSCOMBRE, Jean-Claude. Imparfait et passé composé: des forts en thème/propos. L'information grammaticale, París, v. 55, p. $43-53,1992$.

ANSCOMBRE, Jean-Claude. L'introduction du pronom neutre dans les marqueurs médiatifs à verbe de dire de type Comme dit le proverbe / Como dice el refrán: étude sémantique contrastive d'une contrainte polyphonique. Langages, París, v. 184, p. 13-34, 2011.

AUTHIER, Jacqueline. Ces mots qui ne vont pas de soi. Boucles réflexives et non-coïncidences du dire. París: Larousse, 1995.

BERMÚDEZ, Fernando. La categoría evidencial del castellano: metonimia y elevación de sujeto. Boletín de Lingüística, Caracas, v. 22, p. 3-31, 2004.

BERMÚDEZ, Fernando. Los tiempos verbales como marcadores evidenciales: El caso del pretérito perfecto compuesto. Estudios Filológicos, Valdivia, v. 40, p. 165-188, 2005.

CHAFE, Wallace. Evidentilality in English Conversation and Academic Writing. In: CHAFE, W.; NICHOLS, J. (eds.) Evidentiality. The Linguistic Coding of Epistemology. Norwood: Alex Publishing, 1986. p. 261-272.

CORNILLIE, Bert. Evidentiality and Epistemic Modality in Spanish (Semi-) Auxiliaries. A Cognitive-Functional Approach. Berlin-New York: Mouton de Gruyter, 2007.

DUCROT, Oswald. Le dire et le dit. París: Minuit, 1984.

DUCROT, Oswald. Signification et vérité. Topiques, Buenos Aires, v. 9, p. 61-69, 1987.

DUCROT, Oswald. Sentido y argumentación. In: ARNOUX, E.; GARCÍA NEGRONI, M. M. (eds.). Homenaje a Oswald Ducrot. Buenos Aires: Eudeba, 2004. p. 359-370.

ESCANDELL-VIDAL, Maㅡ Victoria. Futuro y evidencialidad. Anuario de Lingüística Hispánica, Madrid, v. 26, p. 9-34, p. 2010.

GARCÍA NEGRONI, Ma ${ }^{a}$ Marta. Dialogismo y polifonía enunciativa. Apuntes para una reelaboración de la distinción discurso / historia. Páginas de Guarda - Revista de Lenguaje, Edición y Cultura Escrita, Buenos Aires, v. 7, p. 15-31, 2009a.

GARCÍA NEGRONI, Ma Marta. Negación y descalificación. A propósito de la negación metalingüística. Ciências e Letras, San Pablo, v. 45, p. 61-82. 2009b.

GARCÍA NEGRONI, Maㅡ Marta. Ma qué y otra que: dos marcadores de descalificación del español rioplatense. Anuario de Lingüística Hispánica, Madrid, v. 28, p. 57-75, 2012.
GARCÍA NEGRONI, Maㅡ Marta. "Marcadores de discurso y descalificación". In: Actas del VIII Congresso Brasileiro de Hispanistas, Universidade Federal do Rio de Janeiro (en prensa a).

GARCÍA NEGRONI, Mạ Marta. Polifonía, evidencialidad citativa y tiempos verbales. Acerca de los usos citativos del futuro morfológico y del futuro perifrástico. In: GONZÁLEZ RUIZ, R.; IZQUIERDO ALEGRÍA, D.; LOUREDA LAMAS, O. (eds.). La evidencialidad en español: teoría y descripción. Madrid: Vervuert/Iberoamericana (en prensa b).

GARCÍA NEGRONI, Maㅡ Marta y Manuel LIBENSON. Esto/ eso, que $x /$ de que $x$ en contraste. Del significado evidencial perceptivo al significado evidencial citativo. ELUA, Alicante, v. 28, p. $235-250,2014$.

GARCÍA NEGRONI, Ma ${ }^{a}$ Marta; LIBENSON, Manuel. Argumentación, evidencialidad y marcadores del discurso. El caso de por lo visto. Tópicos del seminario, Puebla, 35, en prensa.

KOVACCI, Ofelia. El comentario gramatical. Teoría y práctica, Tomo I. Madrid: Arco Libros, 1990.

KRONNING, Hans. Polyphonie, mediation et modalisation: le cas du conditionnel épistémique. In: BRES, J., HAILLET, P., MELLET S.; NOLKE, H. (eds.). Dialogisme et polyphonie. Bruselas: Editions Duculot, 2005, p. 297-312.

LEONETTI, Manuel y Maㅡ Victoria ESCANDELL-VIDAL. On the Quotative Readings of Spanish Imperfecto. Cuadernos de Lingüística, Madrid, v. X, p. 135-154, 2003.

LÓPEZ FERRERO, Carmen. Funciones retóricas en la comunicación académica: formas léxicas de modalidad y evidencialidad. Signo y Seña, Buenos Aires, v. 14, p. 115-139, 2005 .

NØLKE, Henning. Ne... pas: négation descriptive ou polémique? Contraintes formelles sur son interprétation. Langue Française, París, v. 94, p. 48-67, 1992.

PECHEUX, Michel. L'inquiétude du discours. Textes choisis et présentés par D. Maldidier. París: Editions des Cendres, 1990.

REYES, Graciela. Los procedimientos de cita: citas encubiertas y ecos. Madrid: Arco/Libros, 1994.

RODRÍGUEZ RAMALLE, Maㅡ Teresa. Estudio sintáctico y discursivo de algunas estructuras enunciativas y citativas del español. Revista Española de Lingüística Aplicada, Madrid, v. 21, p. 269-288, 2008.

RODRÍGUEZ RAMALLE, Maㅡ Teresa. Sobre marcadores y su relación con la modalidad evidencial. In: GARCÍA NEGRONI, M. M. (ed.). Marcadores del discurso: perspectivas y contrastes. Buenos Aires: Santiago Arcos, 2014. p. 233-250.

WILLETT, Thomas. A cross-linguistic survey of the grammaticalization of evidentiality. Studies in Language, Berlin, v. 2, p. $51-97,1988$.

Recebido: 15 de outubro de 2015 .

Aprovado: 20 de novembro de 2015.

Contato: mamagn@gmail.com 